\title{
Gore wins approval for his Triana satellite
}

[WASHINGTON] The US space agency NASA and Congress have given the go-ahead to a $\$ 75$ million satellite that will regularly return updated pictures of Earth from space, beginning in early 2001.

Dubbed 'Triana' after the Spanish sailor who was Columbus's lookout, the satellite was conceived by Vice-President Al Gore as an "inspirational" project (see Nature 394, 213 ; 1998). Money for Triana will come from the agency's existing \$1.4 billion budget for Earth science.

A mission concept by Francisco Valero of the Scripps Institution of Oceanography in San Diego has beaten eight other proposals submitted to NASA earlier this year. Triana will be stationed at the L1 'neutral gravity' Lagrange point, 1.5 million kilometres from Earth in the direction of the Sun. It will have a 16-channel, multispectral imaging camera designed by Lockheed-Martin, which has flown previously on other spacecraft. Valero's group also plans to fly a radiometer for measuring the total energy reflected from the Earth, and a small solar wind monitor.

Measuring Earth's reflected energy currently requires piecing together thousands of satellite observations, says Valero. Triana's whole-Earth view will allow scientists to "look at the planet in a new way". Its unique viewing geometry will also show "hot spots" of reflected light, yielding information about forest canopy structure and vegetation health.

Owen Toon of the University of Colorado, who heads one of the interdisciplinary science teams for NASA's Earth Observing System (EOS) of satellites scheduled to

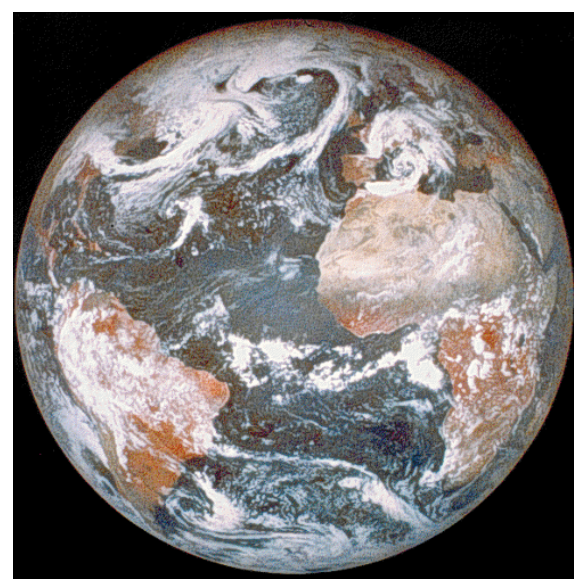

Mosaic: this view of Earth was assembled from 70 images. Triana will capture the scene in one frame.

start launching next year, believes Triana will be an "interesting platform" for observing Earth from a new location. Piecing together the global radiation budget is not a negligible problem, he says.

NASA had no plans to fly an all-Earth radiometer before Gore came up with the Triana concept. Bruce Wielicki of NASA's Langley Research Center in Virginia, the principal science investigator for the EOS CERES instrument that will measure energy reflected from clouds, agrees that the new vantage point could have scientific value. But he believes, like many scientists, that Triana will be "more of an emotional and educational thing" than a research programme. "I don't think it's what [scientists] would have picked a priori," he says.
Wielicki, however, believes the Earth science community could use a high-profile mission to engender public interest, just as the Hubble Space Telescope does for space-based astronomy. "The American public, to be honest, doesn't want just pure science," he says.

NASA, which announced its choice of Valero's design last week, is not saying what other parts of the Earth science programme will be squeezed to pay for Triana, although it has submitted to Congress a plan for "rephasing” some projects. Building the spacecraft and instruments will cost $\$ 35$ million this fiscal year, with the balance spent in 2000 .

Although many researchers are uneasy with the way Triana came about - Gore effectively handed his pet project to NASA as an assignment - it is unlikely to be a major burden on the Earth science community. "It's a small enough project that everybody knows it's not going to break the bank," says Wielicki.

The House of Representatives prevented NASA from spending money on Triana until Congress was convinced it had support in the scientific and/or commercial sectors. But that restriction was removed in the agency's funding bill passed last month. Congressional sources say Gore took his case in person to Jerry Lewis (Republican, California), the House appropriations subcommittee chairman, before the bill was finalized.

Valero's concept leaves the non-scientific aspects of the mission to NASA. The agency says it plans to solicit educational proposals next year and commercial partnerships "over the coming months". Tony Reichhardt

\section{Berkeley teams up with Novartis in $\mathbf{\$ 5 0 m}$ plant genomics deal}

[WASHINGTON] The University of California at Berkeley (UCB) is poised to strike a unique, $\$ 50$ million agreement with the Swiss drug company Novartis. The result will be that a research institute linked to the company will have first rights to a proportion of the genomics research conducted at Berkeley's Department of Plant and Microbial Biology.

The deal is expected to bring the

department up to $\$ 25$ million for laboratory refurbishment and a further $\$ 25$ million in research support over five years, and could be signed by both parties as early as next week. It will differ from normal collaborative agreements between universities and industry because it will involve the entire department, which has 25 professors.

Berkeley will have access to genesequencing technology and database information on plant genomics that it would otherwise be impossible for university researchers to obtain. In return, Novartis
Agricultural Discovery Institute, Inc. (NADII), a major new plant research centre being built at La Jolla, California, will get first rights to negotiate for between a quarter and a third of all the discoveries made at the department.

That fraction corresponds approximately to the proportion of the department's total research budget that will be provided by NADII. The institute is entirely funded by Novartis through a charitable foundation, although the two entities are legally independent.

According to a spokesman for UCB, the university's plant and microbial department has been seeking a corporate partner for some time, and spoke with four contenders before negotiating the deal with Novartis.

The deal has already drawn criticism from some students and staff at UCB. They say that it was drawn up in secret and could threaten academic freedom at the university. But Bob Buchanan, the chairman of the department, argues that “it doesn't impinge on academic freedom at all".

Buchanan adds that the arrangement will bring the department the resources it needs to support graduate students and postdoctoral fellows in the way that medical schools do. "The driving force for this is not the research money, but the training aspect. It will give students opportunities that we couldn't otherwise give them."

Steven Briggs, president of NADII, says it is also seeking "one more academic alliance of similar scope" to that about to be forged with UCB.

NADII was established earlier this year, and expects to move into a new facility with up to 200 scientific staff in two years' time. The research centre is one of a spate of new ventures into plant genomics by corporations. They expect that rapid progress in the discipline will revolutionize not just agriculture but also food production and nutrition. Colin Macilwain 